\title{
Risks of Metabolic Syndrome in Students of the Faculty of Health Sciences
}

\author{
Ersin Öğüş ${ }^{1}$, Mustafa Agah Tekindal', Yelda Ceylan², Merve Demirel ${ }^{2}$, Neşe Emecioğlu², illçim Ercan², Deniz Eroğlu², \\ Sevinç Haner ${ }^{2}$
}

${ }^{1}$ Department of Biostatistics, Başkent University Faculty of Medicine, Ankara, Turkey

${ }^{2}$ Nursing and Health Care, Başkent University Faculty of Health Sciences, Ankara, Turkey

\begin{abstract}
Background: Metabolic syndrome is highly prevalent in the adult population worldwide. Education may play an important role in preventing metabolic syndrome in young adults, especially those who are attending university. Such adults are at a critical point in their lives and make their own lifestyle choices that can affect their future health.
\end{abstract}

Aims: The aims of this study were to determine the metabolic syndrome risk levels of students from the Faculty of Health Sciences.

Study Design: Survey design study.

Methods: In a questionnaire developed by the researchers to collect data in accordance with the relevant literature, the scale of the risk of metabolic syndrome was assessed. A stepwise logistic regression analysis was performed to determine the risks.

Results: Important risk factors for metabolic syndrome were found to be gender, weight gain, "stress eating" excessive amounts of food, sleeping for more than 8 hours a day, feeling tired after sleep, belonging to a divided family, and eating whilst working on the computer

Conclusion: The students from the Faculty of Health Sciences, particularly because they are trained in the health sector, are expected to have more information about the risk factors of metabolic syndrome, and take necessary precautions to prevent it.

Key Words: Metabolic syndrome, risk factors, health education

Received: 11.06.2012

Accepted: 04.02.2013

\section{Introduction}

The prevalence of chronic or non-communicable disease is escalating rapidly around the globe. According to World Health Organisation estimates, by the year 2020, these diseases will account for approximately three quarters of all deaths in the developing world (1). Obesity is a major risk factor for chronic diseases and plays a central role in "insulin resistance" or "metabolic" syndromes, which includes hyperinsulinaemia, hypertension, hyperlipidaemia, type 2 diabetes mellitus, and an increased risk of atherosclerotic cardiovascular disease. Obesity that begins in childhood often precedes the hyperinsulinaemic state $(2,3)$. In this regard, a potentially emerging public health issue for all countries may be the increasing prevalence of childhood obesity that leads to new cases of metabolic syndrome among children and young people, which in turn is likely to create an enormous socioeconomic and public health burden for all nations in the near future. However, little is known about the prevalence of metabolic syndrome in young people because of the limited number of studies, the various definitions used, and the different age groups studied, which make comparisons difficult (4-6).

As in many countries, coronary artery disease and cere- brovascular diseases are the leading causes of death in adults in Turkey. The fight against chronic diseases and primary prophylaxis (prior to the onset of disease, prevention of disease by eliminating risk factors causing it) is important. In order to keep the risk factors under control, one must first determine the prevalence of risk factors and the protection of individuals at risk. In Turkey, the incidence of metabolic syndrome is $28 \%$ in men and $40 \%$ in women. It is obvious that these values are quite high; one in three individuals is known to carry the risk of metabolic syndrome (7-9). The prevalence of metabolic syndrome has doubled in Turkish children and adolescents over the last two decades. Findings indicate that there may be an increase in the future morbidity and mortality from cardiovascular disease, thrombosis, stroke, and diabetes mellitus in developing countries (10).

In light of all of this information, similar to other countries worldwide, Turkey is aware of the importance of metabolic syndrome. Good knowledge of the risks of metabolic syndrome and taking precautions against it are of vital importance to raise healthy generations. One of most important duties of health care professionals is to educate communities. For this reason, it is important that health care workers are made aware of the risk factors of metabolic syndrome during their training. 
As in all other countries, awareness of the risk factors of metabolic syndrome in Turkey carries the highest importance in order to take precautionary measures. In particular, students learning about the field of health should be aware of the risk factors of metabolic syndrome. Therefore, this study was planned to determine the metabolic syndrome risk levels of the students of the Başkent University Faculty of Health Sciences.

\section{Material and Methods}

A questionnaire was designed, consisting of 14 questions, to determine the risk factors of metabolic syndrome according to literature review by the present researchers; this was implemented on students from the Başkent University Faculty of Health Sciences $(7,8,11,12)$.

Reliability analyses were performed for this study and Cronbach's reliability coefficient (Cronbach's alpha) was calculated as 0.887 . This value demonstrates that the scale is reliable.

The questionnaire was administered in two parts. The first part included questions about the socio-demographic characteristics of the students, while the second part contained questions aimed to evaluate the risk factors of metabolic syndrome of the students.

\section{Sample and Data Collection}

There are six departments and 813 students at Başkent University Faculty of Health Sciences. These are Nutrition and Dietetics, Physical Medicine and Rehabilitation, Nursing and Health Care, Health Care Management, Social Services, and Sports Sciences. Two hundred and ninety-three students from these six departments were included in the study by the simple random sampling method. A face-to-face interview was conducted by trained Nursing and Health Care students. Data on demographic characteristics, lifestyle choices, health status, and medical history were collected using a standardised questionnaire. The differences between the departments are not taken into consideration in this study.

\section{Ethical consideration}

This study was planned with the permission of Başkent University, Department of Academic Assessment Coordination. In addition, the information was collected with the informed consent of the students.

\section{Data Analysis}

The data obtained were evaluated using the statistical package SPSS version 17.0 (SPSS for Windows, Chicago, IL, USA). The participants who gave positive responses to at least 8 questions out of 14 were evaluated for the risk of metabolic syndrome. A stepwise logistic regression analysis was performed to determine the risks (13). The aim was to establish the best model by using minimum parameters that could define the relationship between the best fitting and biologically reasonable dependent and independent variables. The goodness of fit of simulation model, calculated according to the method of classification table, accordingly, determined an accuracy of $76.8 \%$ of the final equation.

\section{Results}

\section{Characteristics of the sample}

Basic characteristics of relevant variables and lifestyle information are as follows: the mean age of the participants was $21.13 \pm 2.20$ years; among the students surveyed, $79.5 \%$ were female and $20.5 \%$ were male; the number of course hours per student per week was $3.8 \%$ less than 10 hours, $15.7 \%$ between $10-20$ hours, $51.5 \%$ between $20-30$ hours, and $29 \%$ more than 30 hours. Of the students surveyed, $78.2 \%$ stated experiencing stress before an exam, while $21.8 \%$ did not. Fifty-seven per cent of the students reported eating more food when they are stressed, while the amount of eating did not change for $43 \%$ of the students. The ratio of students who spend less than three hours per day in front of the computer was $69.3 \%$, those who spend 3-6 hours was $25.3 \%$, and those who spend over six hours was $5.5 \%$. A ratio of less than 6 hours sleep per day was $15.4 \%$, between $6-10$ hours of sleep was $81.2 \%$, and more than 10 hours sleep was $3.4 \%$. The percentage of those who stated that they feel rested after sleep was $46.1 \%$ of the population, while $53.9 \%$ still reported feeling tired. The variable rates on the type of family were as follows: those who live in a nuclear family, 84.3\%; a large family, 13\%; and those who live in a divided family, $2.7 \%$. The proportion of students who reported not exercising at all was $43.7 \%$; those who exercise for 1-2 hours per week was $37.5 \%$; those who exercise for $3-4$ hours per week was $10.9 \%$; those who exercise for $5-6$ hours per week was $3.4 \%$; and those who exercise for more than 6 hours per week was $4.4 \%$. The rate of students who have knowledge about the risks of metabolic syndrome was $27.6 \%$, and those who reported a lack of knowledge was $72.4 \%$.

Weekly rates were based on the frequency of eating fast food: the percentage of students who ate 7 meals per week was $72.4 \%$; those who ate $7-14$ meals a week was $22.5 \%$, students who ate $14-21$ times a week was $3.4 \%$; and $1.7 \%$ of the students ate fast food more than 21 times a week. Rates of students in the habit of eating while watching television was $74.1 \%$ and $25.9 \%$ reported not doing so; $50.5 \%$ of students eat while using computers and $49.5 \%$ of them do not.

A stepwise selection of variables was used in this study. Any stepwise procedure for the selection or deletion of variables from a model is based on a statistical algorithm that checks for the "importance" of variables, and either includes or excludes them on the basis of a fixed decision rule. The results obtained by the stepwise logistic regression analysis are shown in Table 1. The constant term in the model is $\beta_{0}=1.235$ and the chosen level of significance was $p<0.05$. When the $p$ value for the test statistics was less than 0.05 , it was concluded that the parameter was significant.

Results of the logistic regression analysis are as follows.

As body weight increases, so does the risk of metabolic syndrome. Considering the interaction between gender and weight, males over 80 kilograms are at a higher risk of metabolic syndrome than females. The risk of metabolic syndrome 
Table 1. Logistic Regression Analysis to Determine the Risk of Metabolic Syndrome Variables

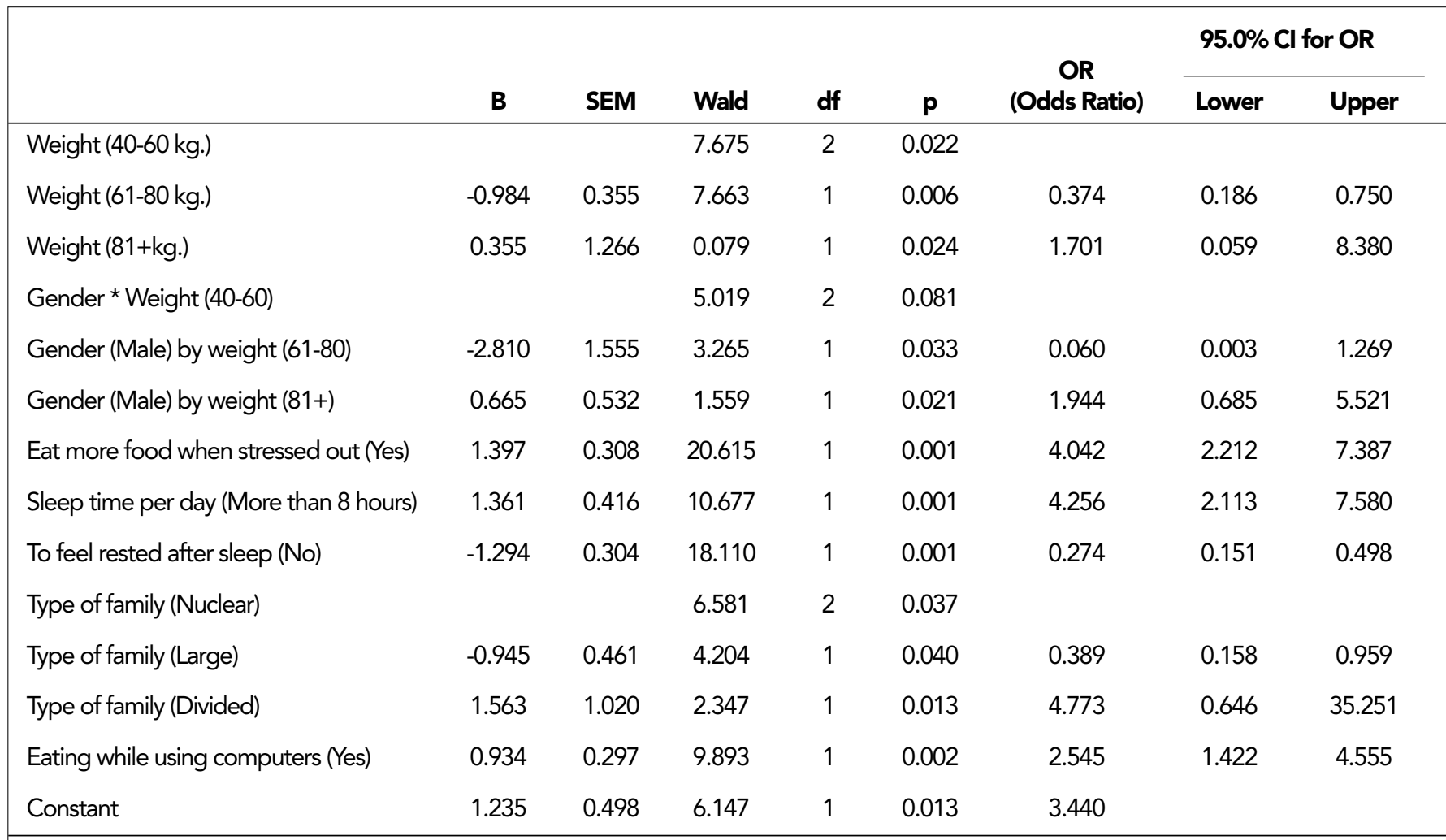

B: Logistic regression coefficient; SEM: Standard error of mean; Wald: Wald statistics; df: Degrees of freedom; $p: p$ value; OR: Odds ratio; $\mathrm{Cl}$ for OR: Confidence interval for odds ratio

for students who are under stress and eat excess food at the same time is four times higher than that of others. More than eight hours of sleep increases the risk of metabolic syndrome. Feeling tired after sleep causes a relatively higher risk of metabolic syndrome compared to rested students after sleep. The risk of metabolic syndrome is higher for children of divided families. The risk of metabolic syndrome for people who eat food while working on the computer is 2.5 times higher than the others.

\section{Discussion}

The students of the Faculty of Health Sciences were evaluated for risk factors of metabolic syndrome. As the number of hours per day spent in front of the computer increases, so does the risk of metabolic syndrome due to sitting motionless for a long period of time. Related to this situation, students whose course hours are higher than normal may be at higher risk of metabolic syndrome. This study's findings are similar to the results of Rashidi et al. (14), who reported that medical university students in Iran are at risk of developing metabolic syndrome. Therefore, planning to increase physical activity and an adequate diet can be an important step towards reducing the prevalence of metabolic syndrome among students. The risk of metabolic syndrome for students who are under stress and eat excess food at the same time was higher than the others. Stress causes some people to eat less, but others to eat more. Epel et al. (15) evaluated that habitually eating more during stressful periods may be a risk factor for the development of metabolic syndrome over time. As a result, 131 medical students at Brown University, USA (55\% women, and mean age $23.75 \pm 3.4$ ), were asked to report their stress-eating tendencies during the baseline and two exam periods over one year (15). Also, Zellner et al. (16) evaluated that stress not only increases the consumption of food in stress-eaters but also moves consumption toward high calorie snack foods that are normally avoided, and away from healthier foods such as fruits. The subjects were 34 undergraduate student volunteers from Montclair State University.

When the scale of the risk of metabolic syndrome was evaluated based on daily sleep time, it was found that sufficient sleep reduces the risk ratio, but excess sleep increases that ratio. There are also studies evaluating the relationship between sleep duration and metabolic syndrome. In a community-based cross-sectional study of 1,214 Chinese people, the odds of having a metabolic syndrome increased by $45 \%$ in both short and long sleepers after adjustment of covariates, compared to those sleeping for 7 to $8 \mathrm{~h}$ per night, and sleep duration was also associated with obesity (17). This finding is also similar to those found by Choi et al. (18). In the Korean National Health and Nutrition Survey, of the 4,222 participants, those who slept $<5 \mathrm{~h}$ and $>9 \mathrm{~h}$ had an increased risk of developing metabolic syndrome. Gangwisch et al. (19) and Lam and Ip (20) found that short sleep duration could be a significant risk factor for diabetes. The association between long sleep duration and diabetes incidence is more likely to 
be due to some unmeasured confounder such as poor sleep quality.

When the body weight of males increases, so does the risk of metabolic syndrome. Huang et al. (21) reported that being overweight increased the risk for experiencing at least one component of metabolic syndrome by approximately three-fold among US College students with an average age of $22.2 \pm 1.7$ years. Thus, men in the age group of $17-26$ who accumulate weight around the waist and abdomen are deemed to be more at risk of metabolic syndrome; this finding is compatible with the literature. Koziarska-Rościszewska et al. (6) evaluated that young men (mean age $24.9 \pm 2.69$ ) are at greater risk than women (mean age $24.4 \pm 2.52$ ) among the young adult students in Poland, whereas this tendency is reversed in elderly people. Age, level of education, and active lifestyle are of great importance in the context of risk of cardiovascular diseases. Determining individuals at risk in the early stages allows the opportunity to correct the metabolic processes, optimise prevention activities (such as lifestyle modification), as well as improve health and life prognosis. Another study presented at the 2009 World Congress on Public Health found that the percentage of students of the Universidad Juárez Autónoma de Tabasco, México have metabolic syndrome due to risk factors during the earlier years (22). Generally, men had more risk factors than the women at this university.

The risk of metabolic syndrome is higher for the children of divided families. Our finding is similar to those of Alciati et al. (23). The type of parental loss during childhood was found to be a significant predictor of metabolic syndrome $(p=0.012$; OR for death 4.75, 95\% Cl 1.36-16.56; OR for separation 2.99, $95 \% \mathrm{Cl} 1.15-7.79$ ).

The habit of eating in front of the computer or television may increase the risk of developing metabolic syndrome. In these cases, the consumption of foods, particularly chocolate, potato chips, corn flakes, or similar junk food, is higher. It is thought that there is a significant correlation between metabolic syndrome and the consumption of such junk foods. Our study had similar findings to the study demonstrating that obesity was observed in students having high calorie junk food at the Medical University in Karachi. The dietary habits and life style of medical students were not healthy; junk food and cola consumption was high, with a predominance of overweight and physical inactivity (24). Universities are an important setting for the surveillance, prevention, and intervention of obesity and metabolic syndrome.

The results of the study support the need to continue screening for all metabolic syndrome criteria in young adults, especially in university students. One of most important duties of health care professionals is to educate communities. For this reason, the students from the Faculty of Health Sciences are expected to have more information about the risk of metabolic syndrome. As a sequel to this study, students may be compared to other faculties.

Ethics Committee Approval: Ethics committee approval was received for this study from Başkent University Department of Academic Assessment Coordination with the Project number B.30.2.BŞK.0.05.10.00-600.43.

Informed Consent: Informed consent was received from the participants of the study.
Peer-review: Externally peer-reviewed.

Author contributions: Concept - E.Ö., M.A.T., Y.C., M.D., N.E., i.E., D.E., S.H.; Design - E.Ö. , M.A.T.; Supervision - E.Ö., M.A.T.; Resource - E.Ö., M.A.T.; Materials- E.Ö., M.A.T., Y.C., M.D., N.E., i.E., D.E., S.H.; Data Collection\&/or Processing - E.Ö., M.A.T., Y.C., M.D., N.E., i.E., D.E., S.H.; Analysis\&/or Interpretation - E.Ö., M.A.T.; Literature Search - E.Ö., M.A.T.; Writing - E.Ö.; Critical Reviews - E.Ö., M.A.T.

Conflict of Interest: No conflict of interest was declared by the authors.

Financial Disclosure: No financial disclosure was declared by the authors.

\section{References}

1. Santos AC, Barros $\mathrm{H}$. Impact of metabolic syndrome definitions on prevalence estimates: a study in a Portuguese community. Diab Vasc Dis Res 2007;4:320-7. [CrossRef]

2. Kelishadi R. Childhood overweight, obesity, and the metabolic syndrome in developing countries. Epidemiol Rev 2007;29:62-76. [CrossRef]

3. Steele RM, Brage S, Corder K, Wareham NJ, Ekelund U. Physical activity, cardiorespiratory fitness, and the metabolic syndrome in youth. J Appl Physiol 2008;105:342-51. [CrossRef]

4. Carnethon MR, Loria CM, Hill JO, Sidney S, Savage PJ, Liu K. Risk factors for the metabolic syndrome. The coronary artery risk development in young adults (CARDIA) study, 1985-2001. Diabetes Care 2004;27:2707-15.[CrossRef]

5. Ekelund U, Anderssen S, Andersen LB, Riddoch CJ, Sardinha LB, Luan J, et al. Prevalence and correlates of the metabolic syndrome in a population-based sample of European youth. Am J Clin Nutr 2009;89:90-6. [CrossRef]

6. Koziarska-Rościszewska M, Panasluk M, Cypryk K. Prevalence of metabolic syndrome and its components in the young adult-students of universities in Lodz, Poland. Pediatr Endocrinol Diabetes Metab 2010;16:277-83.

7. Mollaoglu M, Kars FT, Ozkan TF. The Risk Levels of Metabolic Syndrome and Related Factors among Adults Admitted at a Village Clinic. Journal of Istanbul University Florence Nightingale School of Nursing 2010;18:72-9.

8. The Society of Endocrinology and Metabolizm of Turkey, metabolic syndrome guide 2009; 30/05/2012; www.turkendokrin.org. Turkish.

9. Karadeniz G, Yanıkkerem E, Sarıcan ES, Bulez A, Arıkan C, Esen A. The Metabolic Syndrome Risk In Health Workers In Manisa City in Turkey. Firat Journal of Health Services 2007;2:13-24.

10. Agirbasli M, Adabag S, Ciliv G. Secular trends of blood pressure, body mass index, lipids and fasting glucose among children and adolescents in Turkey. Clinical Obesity 2011;1:161-7. [CrossRef]

11. Gulcu F, Parmaksiz A, Kidir M, Gursu MF. Metabolic Syndrome. Firat Journal of Health Services 2006;1:23-32.

12. Memorial Hospital Guide [Internet]. Istanbul: Memorial Hospital, Internal Medicine Department [updated 30 April 2009; Cited 30 May 2009]. Available from URL: http://www.memorial.com. tr/rehberler/saglik_rehberi/sismanlikla-gelen-tehlike-metaboliksendrom/.

13. Hosmer DW, Lemeshow S. Applied logistic regression, 2 nd ed. USA:Wiley series in probability and statistics; 2000: pp 91-142.

14. Rashidi AA, Parastouei K, Shahaboddin ME. Metabolic syndrome among medical university students in Kashan, Iran. Scientific Research and Essays 2012;7:3549-53.

15. Epel E, Jimenez S, Brownell K, Stroud L, Stoney C, Niaura R. Are stress eaters at risk for the metabolic syndrome? Ann N Y Acad Sci 2004;1032:208-10. [CrossRef] 
16. Zellner DA, Loaiza S, Gonzalez Z, Pita J, Morales J, Pecora D, et al. Food selection changes under stress. Physiol Behav 2006;87:78993. [CrossRef]

17. Hall MH, Muldoon MF, Jennings JR, Buysse DJ, Flory JD, Manuck $\mathrm{SB}$. Self-reported sleep duration is associated with the metabolic syndrome in midlife adults. Sleep 2008;31:635-43.

18. Choi KM, Lee JS, Park HS, Baik SH, Choi DS, Kim SM. Relationship between sleep duration and the metabolic syndrome: Korean National Health and Nutrition Survey 2001. Int J Obes (Lond) 2008;32:1091-7. [CrossRef]

19. Gangwisch JE, Heymsfield B, Boden-Albala B, Buijs RM, Kreier F, Pickering TG, et al. Sleep duration as a risk factor for diabetes incidence in a large US sample. Sleep 2007;30:1667-73.

20. Lam J, Ip M. Sleep and the metabolic sydrome. China Indian J Med Res 2010;131:206-16
21. Huang T, Kempf A, Strother M, Li C, Lee R, Harris K, et al. Overweight and components of the metabolic syndrome in college students. Diabets Care 2004;27:3000-1. [CrossRef]

22. Saraí AB, Quevedo EC, González K, Calderón D, Pati-o MA, González $L Y$, et al. Syndrome metabolic risk factors in university students. 12th World Congress on Public Health 2009 April 27-May 1, Istanbul, TURKEY, Poster presentation, 147.14.

23. Alciati A, Gesuele F, Casazza G, Foschi D. The relationship between childhood parental loss and metabolic syndrome in obese subjects. Stress Health 2013;29:5-13. [CrossRef]

24. Nisar N, Qadri MH, Fatima K, Perveen S. Dietary habits and life style among the students of a private Medical University Karachi. J Pak Med Assoc 2008;58:687-90. 